\title{
PENERAPAN VALUE CLARIFICATION TECHNIQUE (VCT) MODEL ROLE PLAYING DALAM MATA PELAJARAN IPS UNTUK MENEKAN PERILAKU BULLYING SISWA DI SMP NEGERI 4 BANDUNG
}

\author{
Agung Wiradimadja \\ SMP Negeri 4 Bandung, email: wiradimadjaagung@yahoo.com
}

\begin{abstract}
This research was motivated by the concern over student's delinquency phenomenon, especially bullying that have been widespread in education. Like a vicious circle, if bullying was not stopped it's more likely being passed from one generation to others among the victims. Special handling needed in order to break the bullying chain. Based on preliminary observations in SMP Negeri 4 Bandung, some bullying behaviors were visibly done by the students of class VIII - E. Based on the data collected, bullying behavior by students of class VIII - E were quite high, therefore a learning strategy should be formulated in social studies to reduce bullying. The approach used in this study was class activity observation by adopted VCT model of role playing in social science learning implementation. The instrument used was a student's bullying behavior observational sheet and student's social science learning activities field note. Data collection techniques being used were observation, documentation studies and interview, while for the data processing and analysis qualitative and quantitative technique were used. Based on the final research being done, first the implementation started by determined the competency standards and basic competencies in order to arrange the lesson plan being used, second VCT role-playing model was implemented in the social science learning process in the classroom, third the result of the research during the class activities shown that bullying behavior of the students in $1^{\text {st }}$ cycle up to the $3^{\text {rd }}$ cycle were decreased, forth the obstacles from each cycle was reflected, fifth some efforts given to overcome the obstacles appeared from each cycle. Conclusion from the research was, the maximum result achieved in decreasing bullying behavior was in the $3^{\text {rd }}$ cycle.
\end{abstract}

Keyword: Bullying, Value Clarification Technique (VCT).

\begin{abstract}
ABSTRAK
Penelitian ini dilatarbelakangi oleh keprihatinan terhadap fenomena kenakalan remaja khususnya perilaku bullying siswa yang sudah meluas di dunia pendidikan. Seakan-akan seperti lingkaran setan, perilaku bullying ini jika tidak dihentikan akan cenderung menular atau ditularkan kepada korbannya. Hal ini mengisyaratkan perlunya penanganan khusus untuk memutus mata rantai bullying. Berdasarkan observasi awal di SMP Negeri 4 Bandung, nampak perilaku bullying yang dilakukan siswa kelas VIII E cukup tinggi. Maka perlu disusun strategi pembelajaran dalam mata pelajaran IPS untuk menekan perilaku bullying. Metode penelitian yang digunakan adalah penelitian tindakan kelas dengan penerapan metode VCT model role playing dalam mata pelajaran IPS. Instrumen yang digunakan adalah lembar observasi perilaku bullying siswa dan catatan lapangan proses pembelajaran IPS. Teknik pengumpulan data digunakan observasi, studi dokumentasi dan wawancara, sedangkan untuk pengolahan data dan analisis data menggunakan kualitatif dan kuantitatif. Berdasarkan hasil akhir penelitian yang dilakukan, pertama pembelajaran dimulai dengan perencanaan menentukan SK/KD dan penyusunan RPP, kedua penerapan VCT model role playing dalam pembelajaran IPS di kelas, ketiga menunjukan ada penurunan perilaku bullying yang dilakukan oleh siswa pada siklus 1 sampai siklus 3, keempat merefleksikan kendala setiap siklus, kelima upaya menanggulangi kendala setiap siklus. Kesimpulan hasil penurunan perilaku bullying siswa paling tinggi terjadi pada siklus 3 .
\end{abstract}

Kata kunci: Bullying, metode Value Clarification Technique (VCT). 


\section{PENDAHULUAN}

Sekolah merupakan tempat dimana orang melaksanakan pendidikan formal yang ditunjukkan untuk mengasah kemampuan berfikir siswa. Pendidikan juga diarahkan untuk membantu siswa agar mandiri dan dapat membantu siswa dalam menghadapi segala tantangan yang dihadapi. Guru sebagai orang tua murid di sekolah bertugas menstimulus siswa dan membina perkembangan intelektual siswa, membina pertumbuhan nilai-nilai, sikap dan perilaku siswa. Hurlock (dalam Widoretno, 2012:2) menyebutkan sekolah merupakan faktor penentu bagi perkembangan kepribadian anak (siswa), baik dalam cara berpikir, bersikap, maupun cara berperilaku.

Guna mencapai tujuan pendidikan kondisi belajar haruslah berjalan kondusif dan jauh dari kekerasan. Kondisi belajar yang kondusif dan jauh dari kekerasan di sekolah-sekolah di Indonesia dirasa masih belum optimal. Pasalnya masih sering terjadi perilaku kekerasan dan perilaku tidak menyenangkan di sekolah merupakan bentuk perilaku agresif atau yang lebih sering kita kenal dengan bullying atau bully.

Bullying adalah perilaku atau tindakan seseorang mengintimidasi orang lain secara berulang-ulang dengan tujuan untuk menyakiti orang tersebut baik secara fisik maupun psikologis. Olweus dalam Krahe (2005:197) menyatakan bahwa seseorang dianggap menjadi korban bullying bila ia dihadapkan pada tindakan negatif seseorang atau sekelompok orang, yang dilakukan berulang-ulang dan terjadi dari waktu ke waktu. Korban dan teman korban tidak berani melaporkannya lantaran takut akan ancaman yang lebih parah dari pelaku. Coloroso (2006) menyatakan bahwa bullying akan selalu melibatkan adanya ketidak seimbangan kekuatan, niat untuk mencederai, ancaman agresi lebih lanjut, dan teror.

Dampak lain yang dialami pelaku dalam dimensi kognitif dan perilaku adalah terjadinya disfungsi keyakinan dan pemikiran yang irasional bahwa dirinya merasa lebih kuat dan untuk menunjukan kekuatannya tersebut maka pelaku merasa pantas menindas korban yang lebih lemah (Rigby dalam Setiyawati 2012:3).

Gerungan dalam Widoretno, (2012:6) mengemukakan faktor yang mempengaruhi terjadinya bullying antara lain adalah latar belakang keluarga dan pola asuh orang tua. Keluarga menjadi tempat belajar anak. Jika seorang anak dibesarkan dalam keluarga yang sering melakukan bullying, maka anak tersebut mempelajari bahwa bullying adalah perilaku yang biasa diterima, akhirnya anak tersebut meniru apa yang dilakukan oleh orang tuanya. Anak yang berasal dari keluarga yang broken home juga berpotensi menjadi pelaku bullying.

Dampak bullying mengakibatkan korbannya akan merasa tertekan, depresi, pendiam, pemurung, rendah diri dan akhirnya siswa tersebut enggan untuk kembali bersekolah dan bahkan timbul perasaan untuk bunuh diri. Saripah dalam Setiyawati (2010:4), siswa menjadi mudah bosan $(54,94 \%)$, menjadi suka marah-marah $(41,83 \%)$ dan merasa tidak nyaman atau ketakutan di sekolah $(11,41 \%)$, selain itu sebanyak 32 orang siswa $(6,08 \%)$ yang merasa terkadang ingin bunuh diri karena frustasi. Lebih parahnya lagi korban dari bullying berpotensi menjadi berpotensi menjadi pelaku bullying dan ketika anak itu menjadi dewasa sangat berpotensial menjadi perilaku kriminal.

Berdasarkan hasil studi pendahuluan peneliti di SMP Negeri 4 Bandung, hasilnya memperlihatkan adanya kasus bullying yang terjadi di kalangan siswa. Peneliti menemukan beberapa siswa yang berkata kasar kepada temannya, berbicara tidak sopan/merendahkan, ejekan nama orang tua, ejekan nama panggilan, mencemooh, dan jahil terhadap temannya seperti mengganggu temannya yang sedang belajar dengan cara memukul tangan siswa yang sedang menulis dan mendorong kepala siswa yang sedang konsentrasi belajar.

Atas keprihatinan peneliti terhadap permasalahan yang terjadi seperti yang telah diuraikan di atas. Peneliti ingin menekan perilaku bullying pada siswa SMP Negeri 4 Bandung melalui model pembelajaran nilai melalui demontrasi atau memainkan sketsa peran dalam mata pelajaran IPS.

Sapriya (2011:53) menyatakan bahwa pada hakikatnya nilai merupakan sesuatu yang sangat berharga, nilai adalah seperangkat keyakinan atau prinsip perilaku yang telah mempribadi dalam diri seseorang atau kelompok masyarakat tertentu yang terungkap ketika berpikir atau bertindak. Nilai menjadi patokan dan dasar bagi setiap orang dalam 
mengambil keputusan dan berperilaku kesehariannya. Dalam pendekatannya, guru sebagai peneliti ingin menerapkan pembelajaran berbasis nilai melalui Value Clarification Technique (VCT) model Role Playing. Komalasari (2010:105) menyatakan bahwa tujuan dari pembelajaran VCT model role playing dapat melatih siswa menempatkan perasaan dirinya pada perasaan /keadaan orang lain dan melatih siswa terampil dalam mengambil keputusan secara objektif.

\section{METODE PENELITIAN}

Metode penelitian yang digunakan dalam penelitian ini adalah Penelitian Tindakan Kelas (PTK). Kemmis dalam Sanjaya (2011:24) menyatakan bahwa PTK adalah suatu bentuk penelitian reflektif dan kolektif yang dilakukan oleh peneliti dalam situasi sosial untuk meningkatkan penalaran praktik sosial mereka. Metode penelitian tindakan kelas ini sengaja diterapkan untuk memperbaiki sikap dan perilaku siswa kelas VIII - E SMP Negeri 4 Bandung. Dengan menerapkan pembelajaran Value Clarification Technique (VCT) yang dikemas kedalam role playing diharapkan perilaku bullying tidak dilakukan kembali. Teknik pengumpulan data, peneliti menggunakan tiga cara yaitu observasi, studi dokumentasi dan wawancara. Sumber data penelitian yang diperoleh peneliti bersumber dari guru mitra, dan siswa yang menjadi objek penelitian. Adapun tabel 1 adalah variabel dan indikator yang digunakan dalam penelitian ini.

Tabel 1. Identifikasi Variabel dan Indikator

\begin{tabular}{|c|c|c|}
\hline Variabel Laten & Sumber & $\begin{array}{l}\text { Variabel Indikator } \\
\text { (Kategori Bullying) }\end{array}$ \\
\hline $\begin{array}{l}\text { Value } \\
\text { Technique } \\
\text { (VCT) dikemas } \\
\text { dalam Role playing }(\mathrm{X})\end{array}$ & Komalasari (2010) & 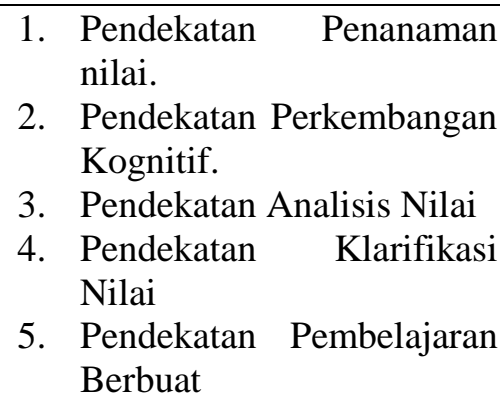 \\
\hline Bullying (Y) & $\begin{array}{l}\text { Krahe (2005); Parsons } \\
\text { (2009); Smith dan Sharp } \\
\text { (1994) }\end{array}$ & $\begin{array}{l}\text { 1. Verbal Langsung. } \\
\text { 2. Verbal Tidak Langsung. } \\
\text { 3. Fisik Langsung. } \\
\text { 4. Fisik Tidak Langsung. }\end{array}$ \\
\hline
\end{tabular}

Data yang didapat oleh peneliti adalah berupa data kualitatif berdasarkan angket penelitian berupa member check yang diisi oleh partner penelitian dan observasi peneliti. Pengukuran data yang dilakukan dalam penelitian ini adalah menggunakan skala nampak dan tidak nampak. Pengolahan data hasil angket penelitian menghasilkan angka persentase siswa yang melakukan bullying dengan mmenggunkan rumus persentase. Dalam penelitian ini, peneliti menargetkan perubahan perilaku bullying siswa menurun hingga dibawah $5 \%$.

\section{HASIL DAN PEMBAHASAN}

Pra-penelitan dilakukan pada awal bulan Februari 2013. Berdasarkan hasil observasi, peneliti melihat siswa sering mencemooh temannya yang salah menjawab pertanyaan dari guru mitra. Bahkan beberapa siswa mengolokolok dengan menyebutkan "Belegug" (Bodoh). Ada siswa dengan sengaja menoyorkan kepala (mendorong kepala) temannya. Adalagi siswa yang mengganggu dengan cara memukul tangan yang sedang menulis, mengambil pulpen temannya. Menertawakan temantemannya yang di jahili. Memplesetkan nama siswa. Ada juga siswa yang memanggil temannya dengan nama orang tua siswa tersebut.

Dari pelaksanaan penelitian tindakan kelas hasil yang diperoleh pada siklus I, siswa nampak masih sering melakukan perilaku bullying kepada teman sekelasnya, tidak perduli 
bahwa dikelas ada dua orang guru. Seakan-akan perilaku ini sudah biasa dilakukan Perilaku bullying yang sering nampak adalah yang termasuk kategori bullying verbal.

Tabel 2. Hasil Penerapan Siklus I

\begin{tabular}{clc}
\hline No: & Kategori Bullying & Persentase \\
\hline 1 & Verbal langsung & $59.76 \%$ \\
2 & Verbal tidak & $18 \%$ \\
& langsung & \\
3 & Fisik langsung & $22.22 \%$ \\
4 & Fisik tidak & $11.72 \%$ \\
& langsung &
\end{tabular}

Pada siklus II, nampaknya ada peningkatan perubahan perilaku siswa. Hasil observasi pada siklus II ini perilaku bullying siswa nampak berkurang dibandingkan dengan hasil pada penerapan siklus I. Namun bullying kategori verbal langsung dan kategori fisik langsung masih nampak mendominasi walaupun tidak sebesar pada siklus I.

Tabel 3. Hasil Penerapan Siklus II

\begin{tabular}{clc}
\hline No: & Kategori Bullying & Persentase \\
\hline 1 & Verbal langsung & $12.87 \%$ \\
2 & Verbal tidak & $5.51 \%$ \\
& langsung & \\
3 & Fisik langsung & $6.53 \%$ \\
4 & Fisik tidak langsung & $3.68 \%$ \\
\hline
\end{tabular}

Pada siklus III, nampaknya mengalami peningkatan perubahan perilaku siswa. Hasil observasi pada siklus III ini perilaku bullying siswa nampak lebih berkurang dibandingkan dengan hasil pada penerapan siklus I dan II.

Tabel 4. Hasil Penerapan Siklus III

\begin{tabular}{clc}
\hline No: & Kategori Bullying & Persentase \\
\hline 1 & Verbal langsung & $3.68 \%$ \\
2 & Verbal tidak & $1.10 \%$ \\
& langsung & \\
3 & Fisik langsung & $2.61 \%$ \\
4 & Fisik tidak langsung & $2.20 \%$
\end{tabular}

Berikut gambar 1 adalah grafik pencapaian hasil dari penelitian tindakan kelas yang dilaksanakan peneliti.

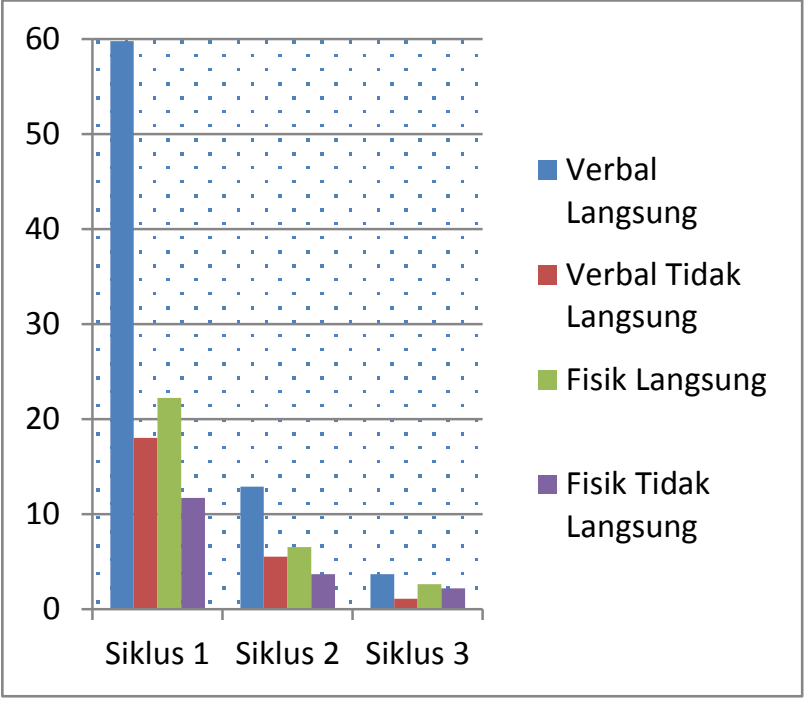

Gambar 1. Grafik Pencapaian Hasil Penelitian

Berdasarkan penerapan tindakan siklus III pada tabel 4 yang menghasilkan nilai persentase bullying > 5\% (kurang dari lima persen) pada semua kategori bullying, maka penelitian tindakan kelas ini dinyatakan berhasil, karena telah mencapat target yang telah dicanangkan dalam penelitian ini sebelumnya.

\section{PENUTUP}

Berdasarkan hasil penelitian tindakan kelas dapat disimpulkan: 1) Perencanaan pembelajaran IPS menggunakan model pembelajaran VCT model role playing untuk menekan perilaku bullying siswa di kelas VIII-E SMP Negeri 4 Bandung dilakukan melalui tahapan menentukan standar kompetensi dan kompetensi dasar agar penerapan penelitian dapat di sesuaikan dengan materi pelajaran yang sedang berlangsung; 2) penerapan model pembelajaran IPS menggunakan VCT model role playing di dalam kelas untuk menuntaskan perilaku bullying siswa kelas VIII - E SMP Negeri 4 Bandung diawali dengan memberikan materi bentuk-bentuk hubungan sosial. Selanjutnya guru menugaskan beberapa orang siswa melakukan beberapa kali role playing, dalam role playing tersebut ada interaksi antar individu maupun kelompok yang menampilkan hubungan yang positif dan ada juga yang menampilkan interaksi dengan hubungan yang negatif. Dalam pelaksanaan tindakan penelitian, guru di dalam kelas membawakan materi pelajaran menggunakan model VCT model role playing; 3) perubahan perilaku bullying siswa 
setelah melaksanakan pembelajaran IPS melalui VCT model role playing mulai dari siklus 1 sampai dengan siklus 3 nampak signifikan; 4) Guru menghadapi beberapa kendala yang dalam menerapkan model pembelajaran IPS menggunakan metode VCT model role playing untuk menuntaskan perilaku bullying siswa kelas VIII E di SMP Negeri 4 Bandung diantaranya masih membuat siswa kebingungan dalam menggali nilai sosial yang terkandung dalam role playing yang dimainkan oleh siswa, belum bisa merasakan empati dari peragaan role playing yang dilihat, belum terbiasa dalam melakukan reka adegan role playing, siswa membutuhkan penjelasan yang lebih dalam dan rinci dalam menggali nilai sosial dan pesan moral yang terkandung dalam role playing, siswa belum paham dengan nilai sosial yang diangkat dalam pembelajaran, siswa membutuhkan waktu yang lebih lama dalam peragaan role playing, dalam menggali nilai sosial dan pesan moral selalu ingin disuapi oleh guru; 5) upaya menaggulangi kendala yang dihadapi peneliti dapat diatasi dengan melakukan upaya perbaikan seoerti berikut: pada siklus guru menstimulus siswa dalam menggali nilai sosial yang terkandung dalam adegan role playing, guru akan menjelaskan empati secara terperici dan terus melatih siswa untuk bisa berempati, reka adegan role playing dibuat sesederhana mungkin, setelah siswa mengomentari adegan role playing, guru akan menggali kembali nilai sosial yang terkandung dalam adegan tersebut dan guru akan memberikan penjelasan hingga siswa paham maksud dari dilaksanakan role playing, memberikan materi tentang nilai sosial dengan jelas agar siswa paham dan mempersilahkan siswa untuk bertanya tentang nilai sosial, meluangkan waktu yang lebih lama untuk melaksanakan role playing.

Kesimpulan akhir dari penelitian yang dilakukan oleh peneliti, dalam penerapan pembelajaran ilmu pengetahuan sosial (IPS) menggunakan model pembelajaran VCT model role playing untuk menekan perilaku bullying siswa di kelas VIII - E SMP Negeri 4 Bandung ini berhasil menurunkan perilaku bullying yang dilakukan siswa pada siklus 1, 2, dan 3 .

\section{DAFTAR PUSTAKA}

Coloroso, Barbara. (2006). Penindasan, Tertindas, dan Penonton; Resep Memutus Rantai Kekerasan Anak dari Prasekolah hingga SMU. Jakarta: Serambi.

Krahe, Barbara. (2005). The Social psychology of aggression: Perilaku Agresif. Yogyakarta: Pustaka Pelajar Offset.

Komalasari, Kokom. (2010). Pembelajaran Kontekstual konsep dan aplikasi. Bandung: PT. Refika Aditama.

Parsons, Les. (2009). Bullied Teacher Bullied Student: Guru dan Siswa yang Terintimidasi Mengenali Budaya Kekerasan di Sekolah Anda dan Mengatasinya. Jakarta: Grasindo.

Sapriya. (2011). Pendidikan IPS Konsep dan Pembelajaran. Bandung: PT. Remaja Rosdakarya Offset.

Sanjaya, Wina. (2011). Penelitian Tindakan Kelas. Jakarta: Kencana Pranada Media Group.

Setiyawati, Tri Murni. (2010). Efektivitas Bimbingan Kelompok Melalui Teknik Role Playing Untuk Menangani Perilaku Bullying: Studi Kuasi Eksperimen terhadap Siswa Sekolah Dasar Laboratorium Percontohan UPI Bandung. Bandung: UPI

Smith, Peter K. and Sonia Sharp.(1994). School Bullying. New York: Routledge.

Widoretno, Hayu. (2012). Teknik Role Playing Untuk Mengurangi Perilaku Bullying Siswa: Studi Pra-Eksperimen terhadap Siswa Kelas VIII SMPN 9 Bandung Tahun Ajaran 2011/2012. Bandung: UPI. 